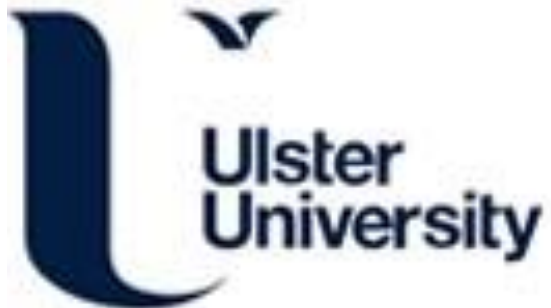

\section{The Potential of Advanced Textiles For Fabric Formwork}

Brennan, J., Pedreschi, R., Walker, P., \& Ansell, M. (2013). The Potential of Advanced Textiles For Fabric Formwork. Proceedings of the ICE - Construction Materials, 166(4), 229-237.

https://doi.org/10.1680/coma.12.00052

Link to publication record in Ulster University Research Portal

\section{Published in:}

Proceedings of the ICE - Construction Materials

Publication Status:

Published (in print/issue): 01/08/2013

DOI:

10.1680/coma.12.00052

\section{Document Version}

Publisher's PDF, also known as Version of record

\section{General rights}

Copyright for the publications made accessible via Ulster University's Research Portal is retained by the author(s) and / or other copyright owners and it is a condition of accessing these publications that users recognise and abide by the legal requirements associated with these rights.

\section{Take down policy}

The Research Portal is Ulster University's institutional repository that provides access to Ulster's research outputs. Every effort has been made to ensure that content in the Research Portal does not infringe any person's rights, or applicable UK laws. If you discover content in the Research Portal that you believe breaches copyright or violates any law, please contact pure-support@ulster.ac.uk. 
Construction Materials Volume 166 Issue CM4

The potential of advanced textiles for fabric formwork

Brennan, Pedreschi, Walker and Ansell
Proceedings of the Institution of Civil Engineers Construction Materials 166 August 2013 Issue CM4 Pages 229-237 http://dx.doi.org/10.1680/coma.12.00052 Paper 1200052

Received 01/12/2012 Accepted 17/05/2013

Keywords: concrete technology \& manufacture/

geotextiles, membranes $\&$ geogrids

\section{The potential of advanced textiles for fabric formwork}

Julie Brennan BA, PhD, PGCert

Reader in Constructed Textiles, School of Art and Design, University of Ulster, Belfast, UK

Remo Pedreschi BSC, PhD, CEng, MICE

Chair in Architectural Technology, University of Edinburgh, Edinburgh, UK
Pete Walker BSc, PhD, MIEAust, CPEng, CEng, MICE

BRE Trust Chair in Innovative Construction Materials, University of Bath, Bath, UK

Martin Ansell BSC, PhD, FIMMM

Reader in Engineering Materials, University of Bath, Bath, UK

A cross-discipline group funded by EPSRC Limesnet, discusses 'Structural woven formwork' from a textile perspective, where the adoption of more sophisticated textile construction enables manufacture of new types of flexible and embedded fabric formworks for potential use in the construction industry, including fibre systems for reinforcing building components, containment structures and layered geo-textiles. In-filled with concrete, aggregate or earth, new formwork fabrics are designed with anisotropic properties to provide enhanced structural performance, permeability and surface finish compared with commercial off-the-shelf fabrics. Dual-function fabrics are introduced that provide permanent formwork through the use of robust internal woven reinforcement and cavity systems to enhance strength. Matched with specific formwork casting and construction methods, these structures could enhance and progress the scope, scale and performance of current formwork, or enable new structures that are currently difficult to achieve. The developments provide key pointers for the progression of the discipline and automation of the process.

\section{Introduction}

Concrete is one of the most widely used materials in the world. Cement, the active ingredient, is a global commodity with annual production in 2011 of $3 \cdot 6$ billion tonnes (see http://www. cembureau.eu/about-cement/key-facts-figures). Production of cement is energy intensive and is the major contributor to the carbon footprint of concrete. Locally sourced materials combined with the readily available supply of cement means that concrete can be made with relatively little in the way of capital equipment and tools. The final ingredient in the production of concrete is the formwork, used to define the shape of the wet concrete as it is cast. The formwork is critical in determining the quality, finish and efficiency of the process.

Traditionally formwork has been made using timber and plywood that can be easily shaped by carpenters, and hence the quality relies largely on the experience and skill of that individual. Perhaps more significantly, although concrete has been described as 'liquid stone', implying limitless shape, the actual geometry of the cast forms is dictated by the materials used for the formwork, namely planar timber, leading to the predominance of rectangular, orthogonal, prismatic elements such as beams and columns. This simplification of the geometry for reasons to avoid complexity in the formwork leads to structural elements and components that are not optimised, and indeed are structurally inefficient and add additional dead weight. A major change to the use of rigid planar formworks is to use flexible formworks produced by cutting and shaping textiles. In recent years there have been a growing number of researchers and practitioners using flexible formworks. A short history of the use of flexible formworks is given by Veenendaal et al. (2011) and Abdelgader et al. (2008). There are many benefits associated with the use of flexible textile formworks compared to rigid formwork (see Chandler and Pedreschi (2008)), most notably

\section{formwork is lighter and easier to construct}

more complex geometries are possible, which can lead to much more structurally efficient elements

improved concrete finish - the permeable nature of textiles reduces surface defects and produces a harder, more durable surface (see Malone (1999) and Orr et al. (2012))

a wide variety of new and exciting architectural forms and finishes are possible (Pedreschi, 2011).

Lee (2011) developed an efficient form-active concrete beam, whose geometry responded to the applied bending and shear forces, resulting in a significant reduction in both the concrete and steel compared to an equivalent rectangular beam. The embodied carbon was reduced by over 30\%. West (2006) and 
Construction Materials

Volume 166 Issue CM4
The potential of advanced

textiles for fabric formwork

Brennan, Pedreschi, Walker and

Ansell
Hashemian (2012) also report resultant savings on efficient forms (Figure 1). Orr et al. (2012) report on the optimisation of double T-beams using fabric formwork.

\section{Current formwork textiles}

To date almost all the textiles used for fabric formwork have been developed for other uses, such as apparel, screening and, most notably, geotextiles. In architectural applications the texture and pattern of fabric is used to create many different types of surface aesthetic effects. Surface texture and finish of formwork panels is mainly determined by the fibre and yarn type. Pedreschi (2011) has conducted substantial trials using a variety of commercially available fabrics, as seen in Figures 2 and 3. Early research identified the key characteristics of a standard range of commercial textiles, assessing their behaviour with in-fill materials and their suitability for formwork. Here 'standard' refers to a conventional industrial woven textile, economically produced in high volumes, which is compatible with textile production and finishing machinery, and constructed using plain or twill weave construction. As seen in progressive formwork concepts by West (2006) and Pedreschi (2011), building components such as columns, beams, vaults, panel products, composites, sub-ground reinforcement, geo-textiles and architectural panels have been studied as exemplars of good practice. Creative and engineered performance forces amalgamated to produce unique and efficient structural elements. Through this work, form-finding, expressive and spontaneous forms have demonstrated the creative potential of the process, as demonstrated by West and Araya (2011).

The variety of textile constructions produces a range of permeability and porosity variations, thus affecting the quality

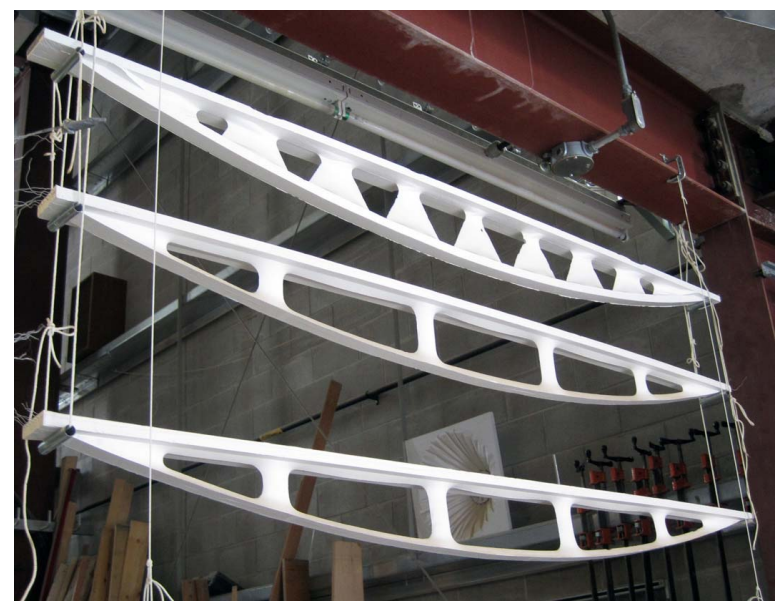

Figure 1. Centre for Architectural Structures and Technology (CAST, University of Manitoba, Canada) prototypes

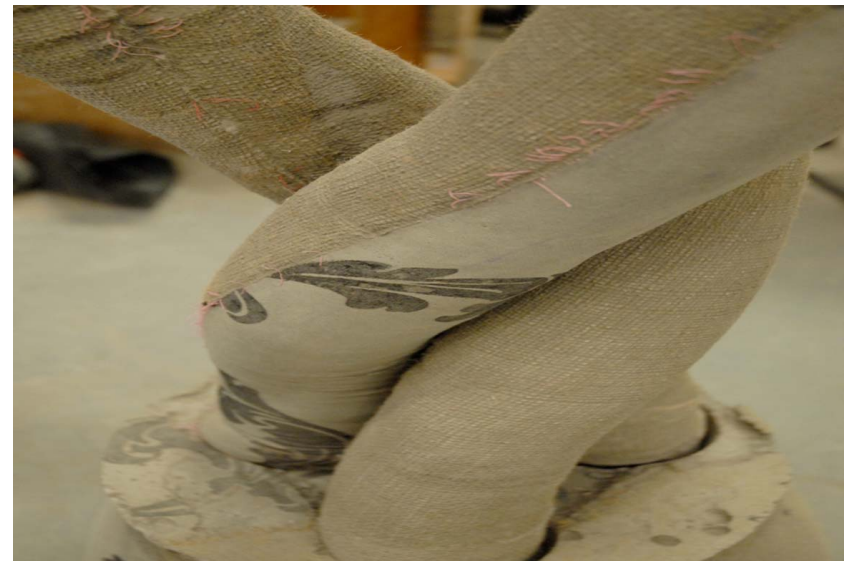

Figure 2. Concrete formed surfaces

and strength of the concrete, which in turn alters the resulting surface quality of formed concrete. The ideal characteristics of formwork textiles are as follows

high tensile strength and stiffness

controlled permeability and porosity

resistance to tearing and bursting and low surface adhesion to the concrete

low creep modulus.

Each of these is discussed further below.

\subsection{High tensile strength and stiffness}

The tensile strength and stiffness of the fabric required will depend on the application (the geometry, degree of restraint and pre-stress in the fabric) and the pressure generated by the wet concrete. Although successful constructions have been made using relatively low strength and stiffness textiles, such as woven cottons, if the application requires significant geometric control, comparatively stiff fabrics, such as polypropylene geotextiles, have been shown to be very effective. Polypropylene geotextiles have the added advantage that the material itself is not sensitive to water, which may cause other materials to stretch. Commercial, off-the-shelf, bi-axial woven geotextiles with an areal density range of 200 $500 \mathrm{~g} / \mathrm{m}^{2}$ are most suitable. Fabrics are constructed from plain weave, the most basic of interlacement constructions with good dimensional stability between warp $(X)$ and weft $(Y)$ axes, offering high tensile strength and isotropic behaviour. Laminated with a non-slip, anti-climatic erosion coating, woven polypropylenes have particularly useful qualities in terms of high tensile strength, permeability, a low creep modulus and resistance to tear; also they are easily stripped. Plain-weave cotton calico, which is used as a textile industry staple, produces highly successful formworks with matt, even surfaces and limited interlacement indentation. 
Construction Materials

Volume 166 Issue CM4
The potential of advanced

textiles for fabric formwork

Brennan, Pedreschi, Walker and

Ansell

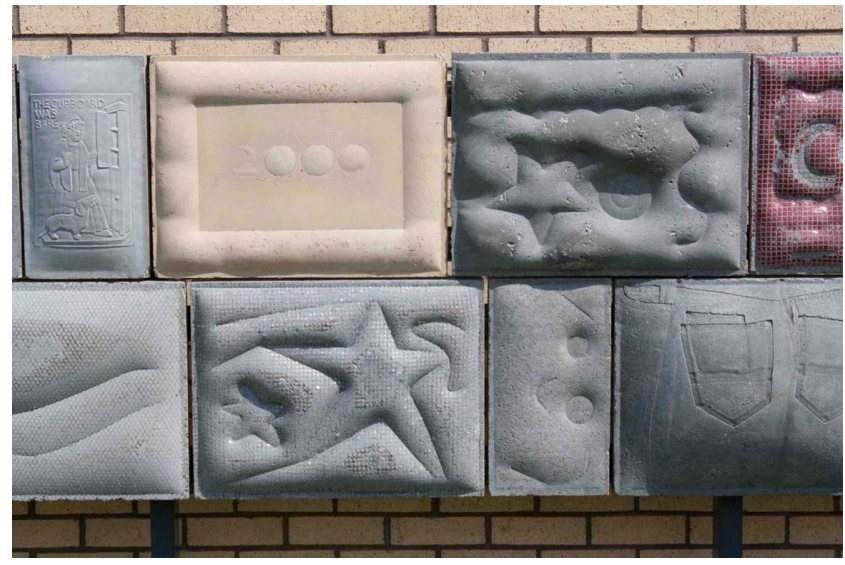

Figure 3. Formwork panels with range of surface finishes

\subsection{Controlled permeability and porosity}

Permeability and aperture size between the interlacing fibres within the fabric structure determine the quality of surface finish and strength of the surface layers of the concrete. The ideal permeability of textile will allow the passage of water but restrict the flow of cement paste. This will result in the outer surface layers of concrete having a dense, cement-rich content that reduces visible defects and increases durability. In terms of fibre porosity, to improve the quality of finished concrete, fibres that have the ability to transport or 'wick' moisture to the outside of the formwork can encourage accelerated drying, better quality curing and good surface quality.

Textiles, such as spacer fabrics or pile woven fabrics, have been used for formworks, most notably by Pronk et al. (2002), and for inflatable concrete shelters such as concrete canvas (see http://concretecanvas.com). $2 \cdot 5 \mathrm{D}$ spacer fabrics have two woven surfaces interconnected by way of pile threads with no accompanying transverse 'weft' threads, producing a fabric with uniform surfaces and a typical depth of $1 \mathrm{~cm}$ (but up to $10 \mathrm{~cm}$ ). Primarily designed for the healthcare and leisure industries, these structures lack permeability and contain a high density of interconnecting threads running between faces, which can cause obstructions to the flow of the in-fill. Therefore, they are not recommended for structures, dependent on size and geometry, where pour length is more critical. Figure 4 shows a curved shell concept cast at the University of Edinburgh where the pour length increased corresponding to the diameter of the conical structure. In-fill technique is critical to prevent air pockets or surface defects.

\subsection{Resistance to tearing and bursting and low surface adhesion to the concrete}

Good fabric integrity, interlocking strength between fibres, lowfriction coating and puncture resistance all provide fabric with

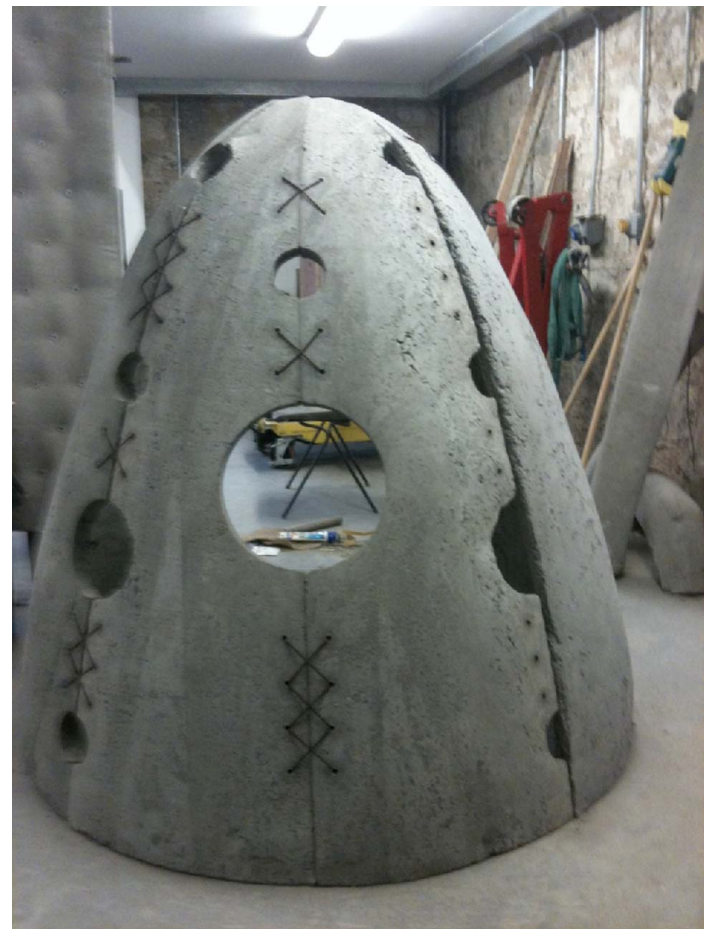

Figure 4. Curved formwork shell structure

good tear resistance. Coatings applied to synthetic textiles during finishing can help to provide ideal fabric for formwork. Fabrics with the highest levels of drape (a collapsible and fluid fabric, often with high sheen that shears easily) are not recommended for structural components as they lack the structural strength and rigidity required. These fabrics are suited for the moulding of decorative fascias. Fabrics with higher stiffness are effective in maintaining streamlined contours in beams and column structures, but can be difficult to manipulate under tension at component edges.

Low-friction polymer coatings and polyvinyl chloride (PVC) applied to fabric or yarns during the textile finishing process enable easy release of sacrificial formwork material, producing highly polished surfaces. Continuous or spun glass fibre (nontexturised), viscose rayon and most synthetic technical textiles provide good materials that release well.

Non-woven and dry-laid fabrics have poor structural integrity owing to their randomly entangled construction and are found to adhere to the concrete, disintegrating on release; unless highly compressed, felted or bonded with another material (West and Araya, 2009). The surface texture and discontinuous fibre lengths of flax and jute fabrics also adhere to the concrete, providing poor release, and can tear the fabric unless blended with a synthetic fibre. 
Construction Materials

Volume 166 Issue CM4
The potential of advanced

textiles for fabric formwork

Brennan, Pedreschi, Walker and

Ansell

\subsection{Low creep modulus}

Some fabrics continue to stretch after the concrete has been placed and this can lead to variations in the geometry. The fabric may not recover after stripping, making subsequent reuse impractical. Control over the geometry of the component with minimal deformation is crucial. Woven textiles are preferred over knitted constructions for this reason. Some natural fibres stretch while damp under sustained tension, resulting in sagging deformations to the component.

By contrast, flexible elastomeric Lycra ${ }^{\circledR}$ material provides unconventional bulged and rounded free-forms. The bulged surfaces, whether intentional or at the will of gravity, creates aesthetic effects. Using gravity and natural weight intentionally to cause 'bowed' curvatures has been attempted by some formwork fabricators (Chandler and Pedreschi, 2008).

\section{Future formwork textiles}

Most formwork research has been undertaken by architects and engineers concentrating on the forms and finishes imparted to the concrete. There has been very little research on the textiles employed. This group has used the collaboration as a catalyst to understand potential advances in formwork construction that can be achieved with the introduction of new textile structures. The ongoing prototype developments were produced in conjunction with industrial manufacturers and on location at the participating UK universities. Areas of focus have been to

(a) use textiles with anisotropic characteristics to reduce the volume of concrete for in-fill by streamlining forms to an efficient tailored shape

(b) improve the structural performance and durability of the concrete system by introducing high-strength textiles with different permeability, interlacement structure and loadbearing capability in comparison to current textiles

(c) use the textile to minimise the use of timber in the vertical supporting framework (as false work and shuttering), thus reducing reliance on timber resources

(d) use textiles for sacrificial formwork, containment structures and as reinforcement, particularly in complex curved geometry where conventional formwork systems may be difficult to construct

(e) assess the versatility of fabrics for use with alternative infills such as aggregate, earth and hemp-lime

(f) consider the manufacturing capability of textile and concrete fabricators in the UK and Europe to produce said materials.

New woven formwork structures such as multiple-layer geogrids and near-net-shaped reinforcements are designed with tailored anisotropic properties to provide alternative performance, permeability behaviour and surface finish. These possess different levels of in-fill retention and containment, porosity and conformability within a given area of the fabric. This enables reinforcement and their subsequent mechanical properties to be manifested where required.

Single-layer fabrics can be extended to include double-, tripleand multiple-layer (three-dimensional (3D)) structures. The fibre proportion and construction density of yarns within and between fabric layers can be varied. Increasing or decreasing aperture sizes within and between the warp $(X)$ and weft $(Y)$ axes of the fabric can provide solid or spaced structures with different reinforcement properties. These include double-layer interwoven tensile grids and experimental fabrics possessing an intermediate system of yarns connecting the surfaces (see Figures 5 and 6).

Tailoring properties, such as increasing the areal density and fibre proportion in a specific zone of the fabric, can offer resistance to localised loading, high pressure or heavy wear. Woven geotextiles (Stewart, 2010) demonstrated how small yet effective variations to weave structure grid size can have a considerable effect on textile properties (and subsequent wear resistance). Grid aperture size can provide containment as well as filtration capability if different concrete aggregate grades are used (Figure 7). Three-dimensional woven containment grids are also an exciting development (Figure 8). These structures

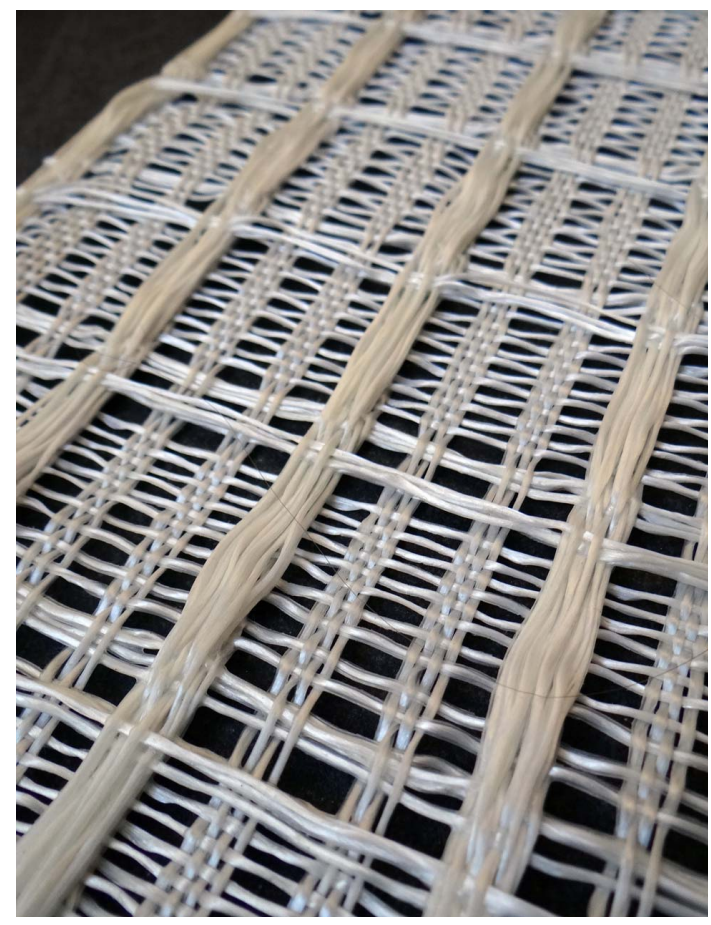

Figure 5. Interwoven geocomposite material 
Construction Materials

Volume 166 Issue CM4
The potential of advanced

textiles for fabric formwork

Brennan, Pedreschi, Walker and

Ansell

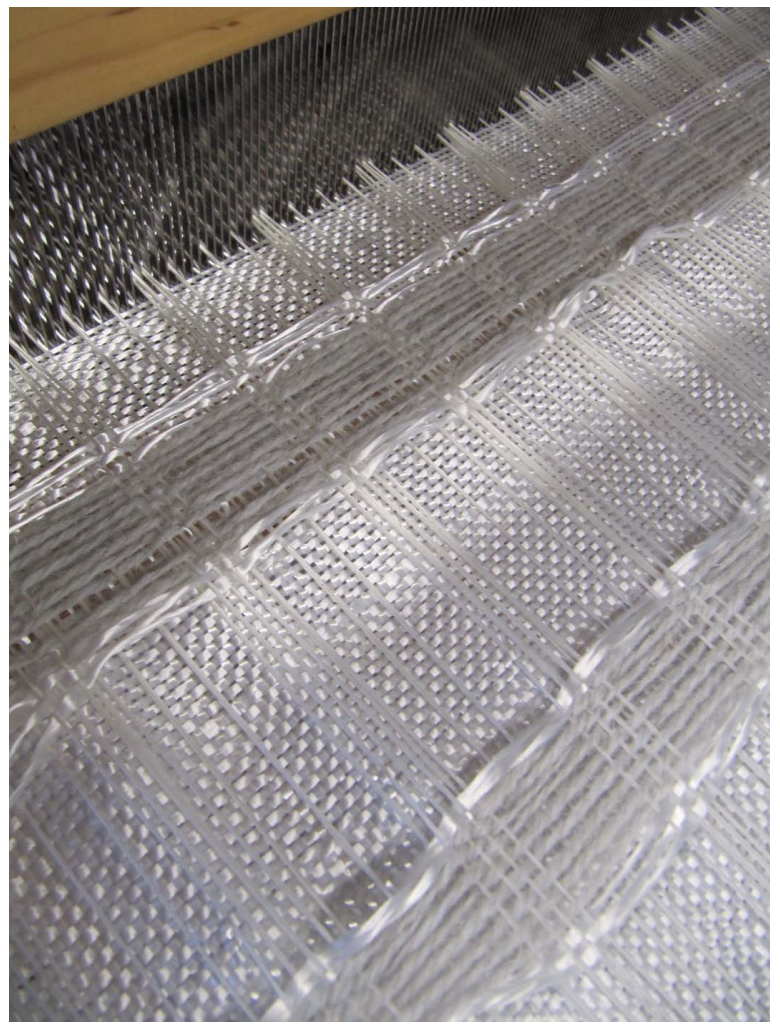

Figure 6. Manufacturing double-layer fabric

are currently being evaluated, for volume production, by an industrial manufacturer.

Free-standing woven cavity constructions can be produced to minimise the reliance on timber frameworks. The outer fabric layers (skin) are connected with an internal system of textile layers achieved by two-dimensional (2D) and 3D weave and stitch technologies in such a way as to produce robust freestanding textile systems with multiple internal cavities to receive in-fill (Soden et al., 2012). The constructions offer improved structural performance and permanent formwork reinforcement with specific 'load' zones by designing a robust, multiple-cavity construction, assembled in such a way as to enhance the compressive strength of the system (see Figures 9 and 10). They could resist high tension forces and the hydrostatic pressure of concrete during casting and could also provide increased resistance to uneven in-fill settling. These are suitable for vertical wall and column elements. Developing textiles specifically for formwork in combination with standard off-the-shelf reinforcement could provide exciting new stitched formwork configurations.

Formwork textile structures described in this paper are distinguishable from fibre-reinforced composite textiles owing

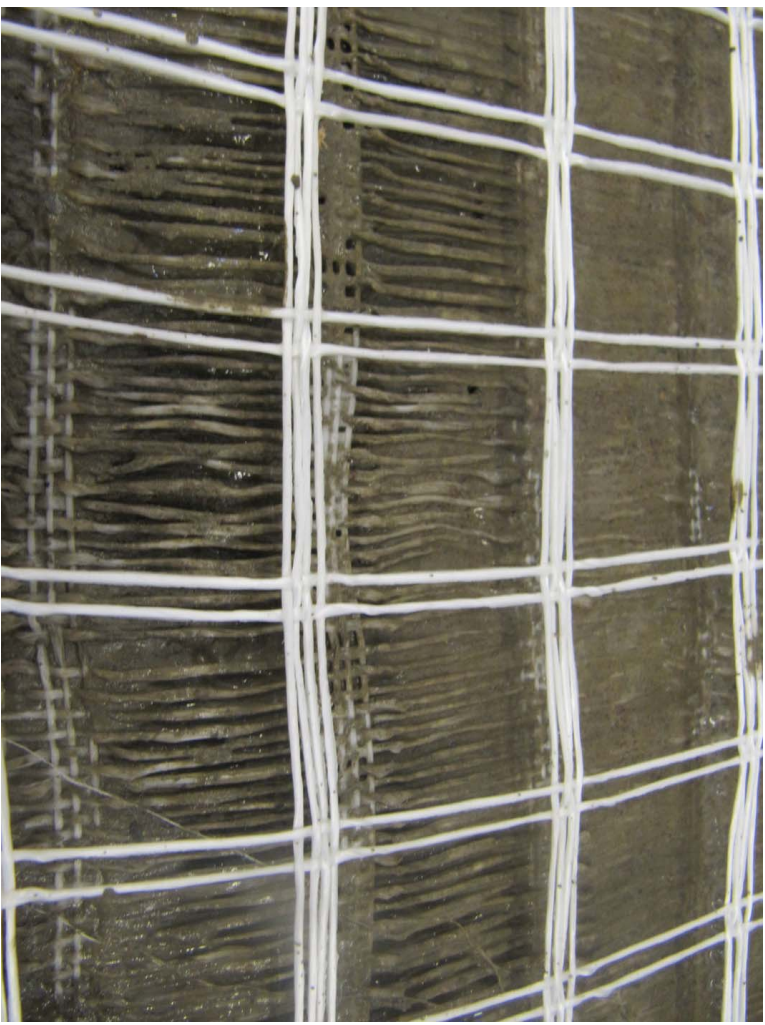

Figure 7. Formwork reinforcement

to the fabric's ability to perform dual functionality as both reinforcement and surface formwork mould simultaneously. The fabric does not need to be completely embedded by the matrix; however, it is often coated with a chemical agent, bitumen or polymer to guard against degradation. The fabric design must take into consideration the controlled wicking of moisture and the fabric's capability readily to host renders such as hemp-lime and antifungal treatments.

Infiltrating the domains of fibre-reinforced concrete, 3D reinforced, axial and multiple-layer textile systems are dominant in engineering composite, reinforced concrete (Brameshuber, 2006) and narrow fabric weaving sectors. Fabric 'preforms' are designed with controlled axial proportions often in fibre volume densities of over $45 \%$, to enable bespoke net-shaping, high stiffness and strength. Such 3D textile systems are described in the built environment as 'permanently participating' fabric formwork. The ability to produce a permanent participating formwork beam has been explained by Orr et al. (2011) as follows.

A participating fabric system in which a composite fabric incorporating carbon fibres acts as both formwork and reinforcement may therefore be advantageous in some situations. 
The potential of advanced

textiles for fabric formwork

Brennan, Pedreschi, Walker and

Ansell

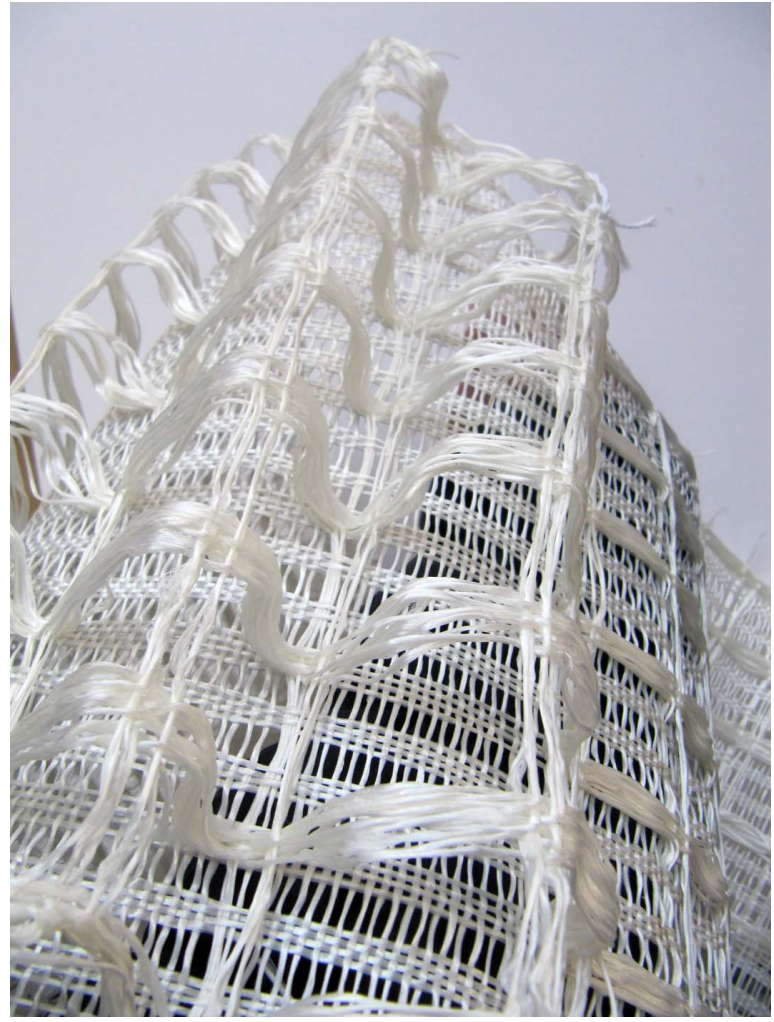

Figure 8. Three-dimensional woven geogrid

Improvements in $3 \mathrm{D}$ weaving capabilities may allow designers to specify carbon fibre weave directions and densities at various points along the length of a beam based on the applied loads. The resulting formwork could then simply be filled with concrete to provide an optimised composite reinforced structure.

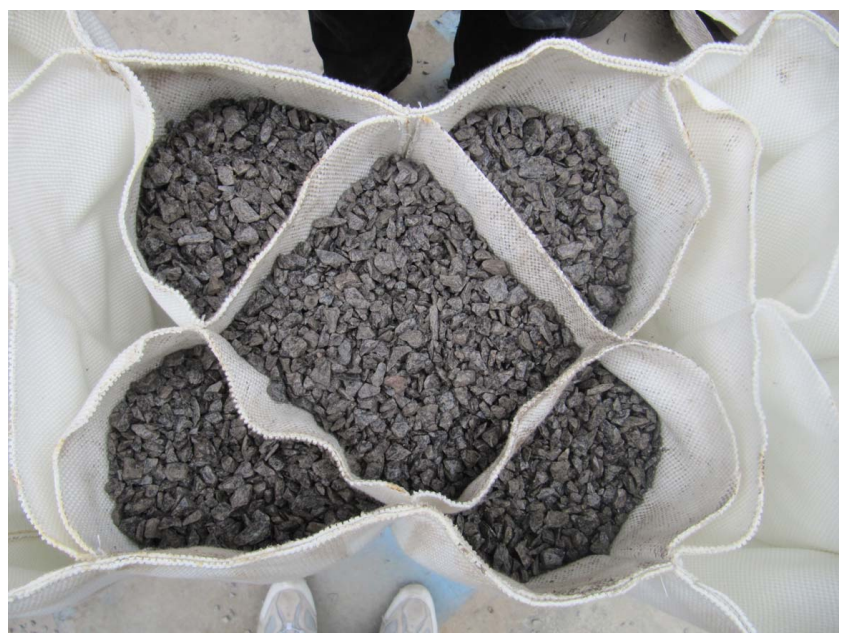

Figure 9. Cavity construction formwork

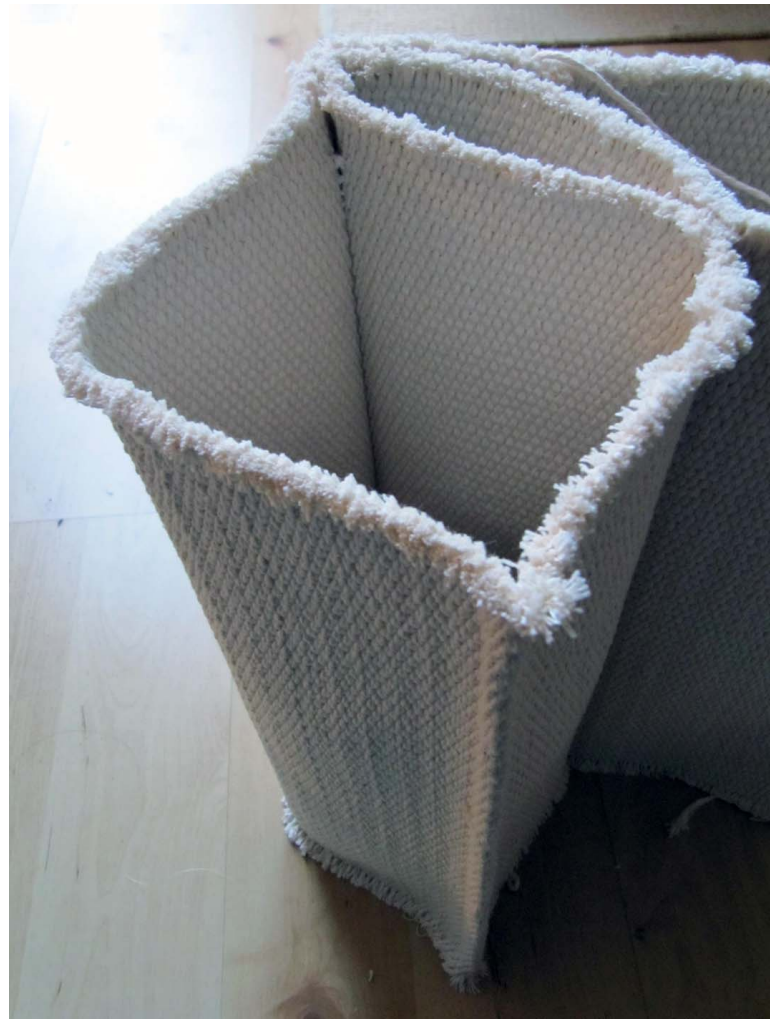

Figure 10. Three-dimensional woven material

Examples of 3D weaves developed as small scale prototypes for new applications are shown in Figures 11 and 12 (Soden and Stewart, 2009).

\section{Opportunities}

Woven textiles using polyester, polyethylene, polypropylene and synthetic fibres currently serve a variety of applications in the civil and infrastructural engineering industry. The weave manufacturer's wide-width availability, produced in mass volumes at the highest production speeds with narrow overheads, makes them attractive to contractors who are keen to maintain traditional materials in a slow-changing and conservative industry. With new materials, textile experts ascertain how to best assign production machinery to manufacture new materials while seamlessly integrating with the established production schedule. They also consider how different structures can be obtained with limited modification to the manufacturing set-up to yield high production rates with limited down-time, thus maximising production efficiencies. These new formworks offer the opportunity for industrial manufacturers to expand their portfolio to include new textile products.

Formwork provides other cost- and time-saving advantages by producing finished cast surfaces without the requirement for 
Construction Materials

Volume 166 Issue CM4
The potential of advanced

textiles for fabric formwork

Brennan, Pedreschi, Walker and

Ansell

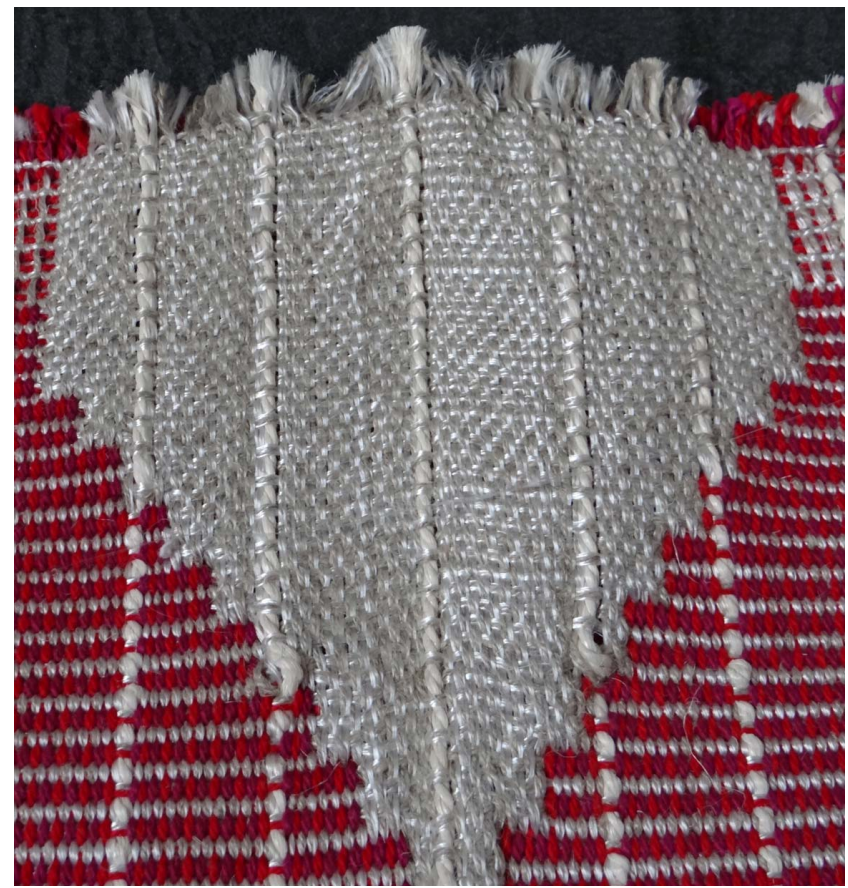

Figure 11. Tapered 3D woven preform

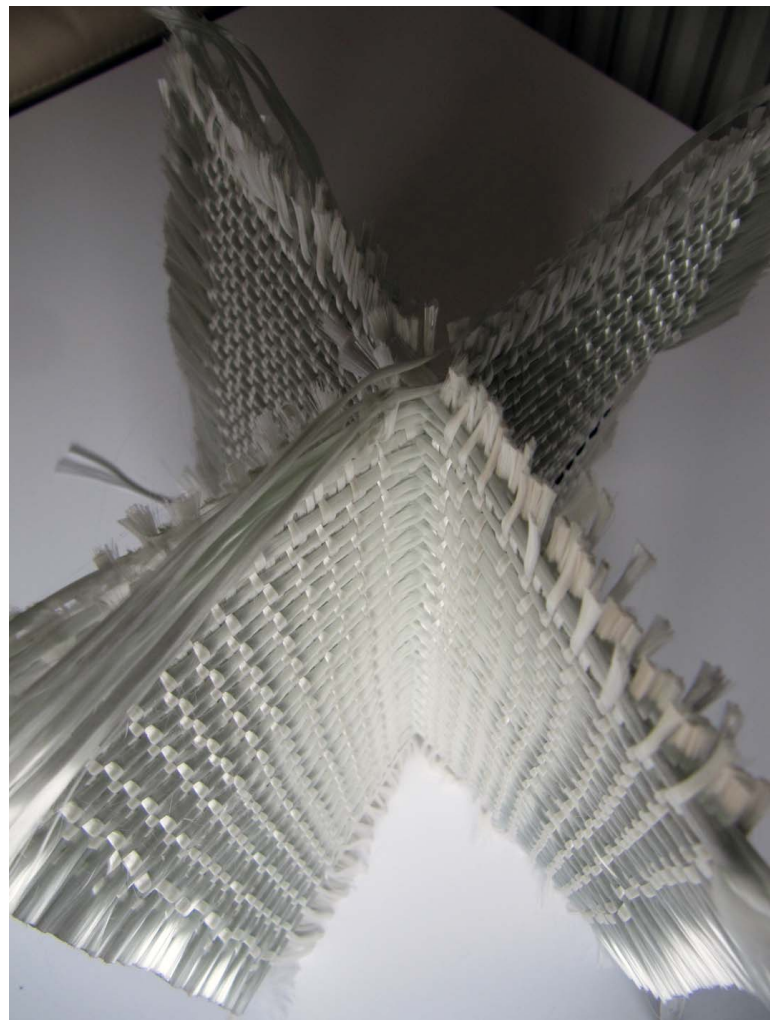

Figure 12. Three-dimensional woven X-profile preform additional cosmetic fascias. Surface texture and finish is important in the development of new contemporary building materials, particularly for designers and architects. Introducing bespoke surface finishes in conventional rigid formwork systems can involve additional, highly specialised (and costly) operations to the formwork, such as the use of latex form liners and post-hardened tooling. Both the geometry and surface are integral to textile formwork systems.

The use of fabric as formwork for doubly curved shells could take advantage of the great inherent strength of shells and their comparative lightness (Cauberg and Tysmans, 2012). Concrete shells were used extensively in the mid-twentieth century, but were used less as the complexity of the formwork required using rigid materials became increasingly more costly (Tang, 2012). Fabric formwork can produce similarly efficient shapes with much greater ease (see Figure 13). Three-dimensional woven textiles offer the opportunity to optimise fully the construction of a new generation of concrete shells by the use of multiple layers, incorporating a layer to control the surface finish and layers to provide embedded reinforcement that follows the natural curvatures of the component.

Geotextiles and geocomposites suffer from elongation, buckling and rupture when stressed in buried containment infrastructure (Brachman and Sabir, 2010). To compensate for poor performance, additional aggregate has to be in-filled, with substantial additional cost resulting in reduced volume capacity. An improved design of buried geocomposite containment fabric such as geogrids and layered grids described earlier could potentially alleviate this problem.

The robust formworks with internal cavities can provide a predominantly free-standing solution owing to their inherent fabric stiffness and stability with minimal support from guide handles. Particularly in a vertical direction, this eliminates the reliance on substantial plywood timber frameworks, where the demands for depth and stiffness require timber to be used in large quantities to prevent deflection.

Timber quality, supply and distribution is problematic in the developing world, and in rebuilding after natural disasters, a formwork construction wall system that does not rely solely on timber or require specialist construction experience, such as the one described here, is of interest. Providing a versatile 'one-stop' solution, it is easily transportable to inhospitable terrain, and is particularly suited for economies where natural disaster has eliminated all vegetation. It is anticipated that the formwork is available on a portable roll (to scale), erected (vertically) on site and suited for earth and even mixed rubble in-fill. It can be rendered using vernacular techniques, thus fitting in with local preferences. The system will combine with other provided materials to form the whole dwelling. The practical work on 
The potential of advanced

textiles for fabric formwork

Brennan, Pedreschi, Walker and

Ansell

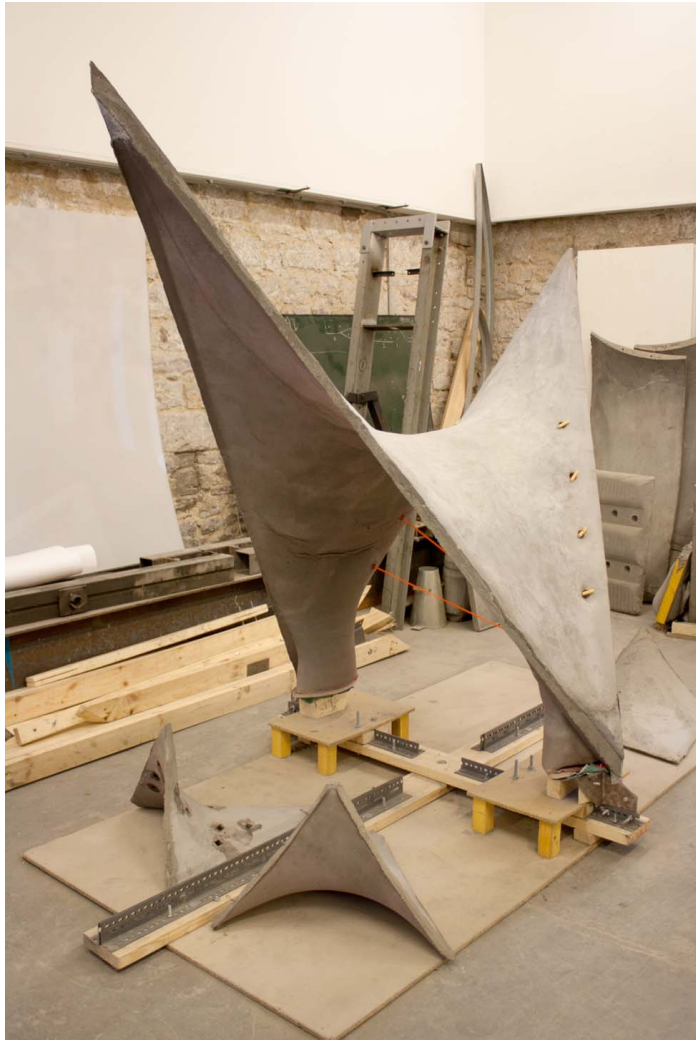

Figure 13. Edinburgh's curved shell experiments

prototype fabric formwork structures has also shown that it is inherently simpler than conventional rigid formwork and can be learned relatively easily by unskilled workers.

The modular design of the formwork enables the system to be designed to suit the particular climate conditions. The textile can incorporate constructions with appropriate aperture sizes and fibres with advanced moisture management capabilities and/or coatings. These permit moisture transportation and controlled wicking of water from the in-fill, allowing accelerated drying and yielding an overall improved strength of the mixture (if concrete) and subsequent quality of the in-fill. This could offer benefits in damp climates prone to flooding where drying and curing are difficult. Conversely, the fabric can be used to maintain a water moisture level where slower rates of curing are needed. The system is basic enough to be easily understood and used by semi- or unskilled workers with appropriate guidance and training.

\section{Challenges}

The paper has described research using textile design to advance future formwork concepts and realise exciting new applications. These ambitions come with challenges that have to be considered including the following points.
The question of up-scaling from textile prototype to full production is challenging for the textile manufacturer when attempting to introduce new systems and products. The balance between standardised and bespoke production, and matching production volumes to construction project needs, will be a major practical consideration.

- The additional performance as balanced against additional cost must be considered. Both stitched and fully woven elements have been considered relevant for this investigation, providing both economical and more costly tailored solutions. More rapid uptake of the 'lower tech' materials is expected, as they offer less of a 'technology jump' to current product and can be manufactured readily using existing setups in both the UK and Asia.

New technology formworks can be described as a disruptive technology. Christensen (1997) challenges the original paradigm, in this case rigid formwork. Such technologies often supplant existing technologies that originate from 'niche' applications.

- It will be necessary to demonstrate to architects and contractors that these technologies present a new approach relying on textile technology, rather than the resurrection of an older construction technology.

The anticipated applications for formwork textiles will most likely consist of a series of different and quite distinct sectors:

a standardised systems for the economic production of structural elements such as beams, columns and walls

nighly bespoke structural elements for exclusive applications

- low-technology systems for rapid deployment and self-build in post disaster reconstruction

architectural finishes and façade systems.

The technology readiness level of some of the proposed formwork types is still in commercial infancy (bespoke vaulted structures), whereas others are nearing (low-tech disaster systems) or have already reached (façades and panels) commercial readiness.

\section{Conclusion}

There is now sufficient research on the use and application of flexible formworks with textiles to prove the effectiveness of the concept. However, it is not a panacea for all the potential applications of concrete. What is clear is that once the key characteristics of the evolving technology are understood, then there are considerable benefits and merits in comparison with traditional rigid formworks. To date most of the research has concentrated on the vicarious use of textiles developed for other applications. This paper has sought to demonstrate that, taken from the viewpoint of the textile technologist and considering the development of textiles specific to concrete, the range and effectiveness of the technology can expand much further. 


\section{REFERENCES}

Abdelgader H, West M and Górski J (2008) State-of-the-art report on fabric formwork. Proceedings of International Conference on Construction and Building Technology, University Technology Petronas, Kuala Lumpur, Malaysia, pp. 93-106.

Brachman RWI and Sabir A (2010) Geomembrane puncture and strains from stones in an underlying clay layer. Geotextiles and Geomembranes 28(4): 335-343.

Brameshuber W (ed.) (2006) Report 36: Textile Reinforced Concrete - State of the Art Report. RILEM Committee TC201, RILEM, Germany, pp. 16-21.

Cauberg N and Tysmans T (2012) Shell elements of textile reinforced concrete using fabric formwork. Case Study Advances in Structural Engineering 15(4): 677-690.

Chandler A and Pedreschi R (2008) Farbric Formwork. RIBA Publishing, London, UK.

Christensen C (1997) The Innovator's Dilemma: When New Technologies Cause Great Firms to Fail. Harvard Business School Press, Boston, MA, USA.

Hashemian F (2012) Structural Behaviour and Optimization of Moment-Shaped Reinforced Concrete Beams. PhD thesis, University of Manitoba, Winnipeg, Canada.

Lee SH (2011) A Study of Construction Methodology and Structural Behaviour of Fabric Formed Form-efficient Reinforced Concrete Beams. PhD thesis, University of Edinburgh, UK.

Malone P (1999) Use of Permeable Formwork in Placing and Curing Concrete. US Army Corps of Engineers, Washington, DC, USA, Technical Report TR SL-99-12.

Orr JJ, Darby AP, Ibell TJ, Evernden MC and Otlet M (2011) Concrete structures using fabric formwork. Structural Engineer 89(8): 20-26.

Orr JJ, Darby AP, Ibell TJ and Evernden M (2012) Optimisation and durability in fabric cast double T-beams. Proceedings of the 2nd International Conference on Flexible Formwork, Bath, UK, pp. 268-279.

Pedreschi RF (2011) The use of fabrics as formwork for concrete structures and elements. In Proceedings of 5th International Conference on Textile Composites and Inflatable Structures, Structural Membranes 2011 (Kroplin B and Onate E (eds)). CIMNE, Barcelona, Spain, pp. 421-431.

Pronk ADC, Veldman SL and Houtman R (2002) Making double curved forms with the use of a 3D fabric. In Space Structures 5 (GAR Disney Parke (ed.)). Thomas Telford, London, UK, pp. 541-546.

Soden JA and Stewart GFJ (2009) Natural fibre composites with $3 \mathrm{D}$ woven reinforcements for new application areas keynote address. In Proceedings of Natural Fibres '09 (BC Suddell (ed.)). Institute of Materials, Minerals and Mining, London, UK.

Soden J, Pedreschi R, Walker P and Ansell MP (2012) Woven Structural Formwork. Limes Net Low Impact Materials and Innovative Engineering Solutions for the Built
Environment, International Research Mission Case Study IMF003. See http://limesnet.org/wp-content/uploads/2012/ 09/IMF003_finalLimesnetCase-study_Soden.pdf (accessed $11 / 03 / 2013)$.

Stewart GJ (2010) The Development of Multi-layer Woven Structures for Use in Road Construction Geotextiles. $\mathrm{PhD}$ thesis, University of Ulster, Londonderry, UK.

Tang G (2012) The rise and fall of the thin concrete shell. Proceedings of the 2nd International Conference on Flexible Formwork, Bath, UK, pp. 334-345.

Veenendaal D, West M and Block P (2011) History and overview of fabric formwork: using fabrics for concrete casting. Structural Concrete 12(3): 164-177.

West M (2006) Material Reduction: Efficient Fabric Formed Concrete. CAST Centre for Architecture Structures and Technology, University of Manitoba, Winnipeg, Canada, Research Report NA05_CEJNW.

West M and Araya R (2009) Fabric formwork for concrete structures and architecture. In Proceedings of International Conference on Textile Composites and Inflatable Structures, Structural Membranes 2009 (Kroplin B and Onate E (eds)). CIMNE, Barcelona, Spain, pp. 1-4.

West M and Araya R (2011) Fabric formwork for concrete structures and architecture. In Proceedings of International Conference on Textile Composites and Inflatable Structures, Structural Membranes 2011 (Kroplin B and Onate E (eds)). CIMNE, Barcelona, Spain, pp. 1-4.

\section{WHAT DO YOU THINK?}

To discuss this paper, please email up to 500 words to the editor at journals@ice.org.uk. Your contribution will be forwarded to the author(s) for a reply and, if considered appropriate by the editorial panel, will be published as discussion in a future issue of the journal.

Proceedings journals rely entirely on contributions sent in by civil engineering professionals, academics and students. Papers should be 2000-5000 words long (briefing papers should be 1000-2000 words long), with adequate illustrations and references. You can submit your paper online via www.icevirtuallibrary.com/content/journals, where you will also find detailed author guidelines. 